\title{
Therapeutic potential of boron-containing compounds
}

\begin{abstract}
Relative to carbon, hydrogen, nitrogen and oxygen, very little is currently known about boron in therapeutics. In addition, there are very few boron-containing natural products identified to date to serve as leads for medicinal chemists. Perceived risks of using boron and lack of synthetic methods to handle boron-containing compounds have caused the medicinal chemistry community to shy away from using the atom. However, physical, chemical and biological properties of boron offer medicinal chemists a rare opportunity to explore and pioneer new areas of drug discovery. Boron therapeutics are emerging that show different modes of inhibition against a variety of biological targets. With one boron-containing therapeutic agent on the market and several more in various stages of clinical trials, the occurrence of this class of compound is likely to grow over the next decade and boron could become widely accepted as a useful element in future drug discovery.
\end{abstract}

The physical, chemical and biological properties of boron offer medicinal chemists a rare opportunity to explore and pioneer its utility in chemotherapeutics. However, up until the last few years, boron has mostly been overlooked by medicinal chemists in their design of drug molecules. In trying to discern why boron has not been widely considered, we found a common belief within the medicinal chemistry community that boron is toxic. However, as we have investigated this claim, we have found it to be largely unfounded. The belief that boron is toxic most likely comes from the fact that boric acid $\left(\mathrm{B}[\mathrm{OH}]_{3}\right)$ is an ingredient of ant poisons. However, boric acid, has an $\mathrm{LD}_{50}$ of $2660 \mathrm{mg} / \mathrm{kg}$ (rat, oral), which is similar to regular table salt at $3000 \mathrm{mg} / \mathrm{kg}$ (rat, oral) [101]. Another source of the toxicity concern may have arisen from the toxicity of Velcade ${ }^{\circledR}(\mathbf{4 9})$, the only boron-based therapeutic currently on the market and widely prescribed by oncologists. Velcade is approved for the treatment of multiple myeloma and works through inhibition of the proteasome. Recently, research has shown that the toxicity of Velcade is due to its mechanism of action and not simply because boron is present in the molecule [1].

The overwhelming data for the safety of boron are to be noted. Boric acid is the main ingredient in 'Goop' the soft semi-solid, often brightly colored toy that children enjoy squeezing through their fingers; boric acid is used as a preservative in eye wash and in vaginal creams; it is used as a buffer in biological assay solutions; boron is also found in high concentrations in fruit, vegetables and nuts. We consume in the range of $0.3-4.2 \mathrm{mg}$ of boron per day [2] and it is considered an essential plant nutrient, although its biological functions are currently unknown. Studies at Anacor Pharmaceuticals found background concentrations of boron in mouse plasma samples of approximately 200 ng/ml [Wheeler C, Unpublished Data]. Therefore, it does appear that the body is familiar with boron. The boronic acid group in Velcade has been shown to be metabolized to boric acid and the body seems to manage its metabolism and excretion [3]. Paraboronophenylalanine was used for boron neutron-capture therapy (BNCT) and found to be safe in multiple species including human. The $\mathrm{LD}_{50}$ values of free base paraboronophenylalanine were determined to be more than $3000 \mathrm{mg} / \mathrm{kg}$ in rat by intraperitoneal or subcutaneous administration. In repeat dose studies in rats, paraboronophenylalanine was administered subcutaneously for 28 days and the $300-\mathrm{mg} / \mathrm{kg}$ group exhibited no significant finding when compared with the control group [4]. In humans, paraboronophenylalanine was administrered via infusion as a complex with fructose, up to $900 \mathrm{mg} / \mathrm{kg}$ of bodyweight [5], and BSH $\left(\mathrm{Na}_{2} \mathrm{~B}_{12} \mathrm{H}_{10}-\mathrm{SH}\right)$, another boron therapeutic for BNCT, was administered at the $100-\mathrm{mg} / \mathrm{kg}$ bodyweight level [6]; both proved to be safe and well tolerated. From all these data, we have concluded that boron is not an inherently toxic element, such as mercury, and can be considered by medicinal chemists for use in therapeutics. The toxicology question now is not what happens to boron, but what happens to the

\author{
Stephen J Bakert, \\ Charles Z Ding, \\ Tsutomu Akama, \\ Yong-Kang Zhang, \\ Vincent Hernandez \& Yi Xia \\ ${ }^{\dagger}$ Author for correspondence \\ Anacor Pharmaceuticals, Inc., \\ 1020 East Meadow Circle, \\ Palo Alto, CA 94303, USA \\ Tel.: +l 6505437500 \\ Fax: +l 6505437660 \\ E-mail: sbaker@anacor.com
}

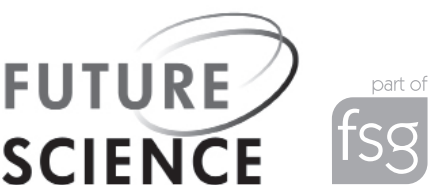


DIAZABORINE

$\mathrm{R}-\mathrm{B}(\mathrm{OH})-\mathrm{N}=\mathrm{N}-\mathrm{R}^{\prime}$, sixmembered heterocycle ring containing a boron, two nitrogen and three carbon atoms rest of the molecule should boron be eliminated from the parent molecule, a standard question for any drug candidate of nonboron origin.

Why do we not have more US FDA-approved boron-containing therapeutics to date? Our primary conclusion is that it is because the organoboron chemistry field is still in its infancy and we do not have a very large portfolio of chemical reactions to introduce boron into organic molecules, nor do we have a good understanding of the compatibility of boron-containing molecules in common synthesis. Over the last two decades, and since Suzuki-Miyaura coupling reactions have become more widespread, there has been a significant increase in organoboron chemistry, which has led to the introduction of new catalysts and new methods of incorporating boron into organic molecules and has provided more insight to the chemical compatibilities of organoboron compounds. This chemistry development is now allowing medicinal chemists to build drug-like boron-containing molecules to finally explore the usefulness of boron in chemotherapeutics.

Similar to hydrogen, carbon, nitrogen and oxygen, boron is, quite simply, another useful atom! Boron can be considered the equal and opposite of nitrogen. Nitrogen is a Lewis base, boron is a Lewis acid; nitrogen has a full $p$-orbital (lone pair), boron has an empty $p$-orbital; nitrogen is nucleophilic, boron is electrophilic; nitrogen sits to the right of carbon in the periodic table, boron sits to the left. Boron in organic molecules is most commonly present as a boronic acid group ( $\left.\mathrm{R}-\mathrm{B}[\mathrm{OH}]_{2}\right)$, where its pKa usually ranges from 7 to 9 , considerably higher than carboxylic acids. This means that, at physiological $\mathrm{pH}$, boronic acid is uncharged and in the trigonal planar sp ${ }^{2}$ form (APPENDix, l). At $\mathrm{pHs}$ above its $\mathrm{pKa}$, a hydroxy group coordinates to the empty $p$-orbital, forming a dative bond, and boron is in a tetrahedral $\mathrm{sp}^{3}$ form (2).

The empty $p$-orbital can also be occupied by a lone pair from other nucleophiles, including alcohols and amines, allowing boron to form a dative bond with biological nucleophiles such as enzyme residues, including serine, and hydroxy groups from carbohydrates and nucleic acids. Boron can form a bond with a therapeutic target that is neither ionic nor an irreversible covalent bond. Also, the pKa of boron can be tuned by chemical modification of the molecule to make it a stronger or weaker electrophile. Modulation of electronic and peripheral substitutions can allow boron to improve its selectivity towards its desired target. Boronic acids can also form borate esters with alcohols. However, these are usually unstable and hydrolyze easily in water. Under certain circumstances, the stability of these borate esters can be increased through intramolecular cyclization, (e.g., forming a diester with both hydroxyl groups of a 1,2-cis-diol, such as ethylene glycol, to form a 5-membered dioxaborolane ring). Substituted cis-diols are even more stabilized, due to steric hindrance preventing water approaching the boron and subsequent hydrolysis. The properties, preparation and applications of boronic acids have been comprehensively reviewed [7].

Boron in therapeutics has been reviewed in depth [7-9]. This review is intended to describe some of the recent advances since those earlier reports, as well as to describe some older chemistry of the diazaborines and to make a judicial prediction about the potential future of boron in drug discovery.

\section{Therapeutic areas containing boron-based therapeutics \\ - Diazaborines \& enoyl reductase Early history of diazaborines}

One of the first classes of boron-containing compounds evaluated as therapeutics was the diazaborines [10]. Diazaborines were first synthesized by Dewar who was investigating the 'nonbenzenoid' aromaticity of heterocycles [11]. Dewar did not report their medicinal application, but rather that they were tool compounds to demonstrate the potential of replacing the $\mathrm{C}-\mathrm{C}$ unit in aromatic compounds with the isoelectronic B-N bond. However, it was Gronowitz who saw a similarity with the hydrazone-containing nitrofuran antibiotic nitrofurantoin (3); diazaborines, he reasoned, contained an internal hydrazone and might also share the same antibiotic activity.

His work demonstrated the first reported antimicrobial activity for a boron-containing compound $[12,13]$. Starting first with structurally similar nitrothiophene (4), Gronowitz quickly established that the nitro substitution on the ring was not necessary and that the most dramatic impact on activity was observed when changing the hydrazine component. A strong preference for 2- $N$-sulfonyl substitution in analogs possessing antibacterial activity was noted and served as the template for future research. Several patents followed, demonstrating the apparent interest in this area and culminating in the largest such evaluation being published by Sandoz Pharmaceuticals [14]. In this study, the MIC activity of 80 different diazaborines 
was consistent with previous observations that activity was confined almost exclusively to Gram-negative bacteria. It was generally established that the ranking of potency, relative to the arene ring, followed the order: thienodiazaborines, benzodiazaborines, furanodiazaborines, with pyrolodiazaborines being inactive. In the $2-N$-sulfonylalkyl-thienodiazaborine series, the effect of homologating the alkyl chain was striking, with 5 having a high MIC against Escherichia coli of more than $50 \mu \mathrm{g} / \mathrm{ml}$, compared with $6.25 \mu \mathrm{g} / \mathrm{ml}$ for 6 . Methylation of the thiophene ring gave a slight boost in potency to provide the most promising diazaborine reported (Sa 84474 [7]) with an MIC of $1.25 \mu \mathrm{g} / \mathrm{ml}$.

To better understand the requirements for activity, a nonboron analog, 4-hydroxy-3-( $p$-tolylsufononyl) isoquinoline, was prepared and found to be inactive. It is important to note that these synthetic efforts were not guided by knowledge of the mechanism of action. In fact, the target was initially believed to be lipopolysaccharide synthesis [15], which was consistent with the observation that activity was confined almost exclusively to Gram-negative bacteria. Subsequent studies would reveal the actual target to be fatty acid biosynthesis, but it took another 12 years until the crystal structure was reported [16,17].

Investigation into the structure-activity relationships of diazaborines during this time was almost exclusively limited to diazaborines containing the sulfonyl side chain. Problems with this particular class of diazaborine are evident from the literature as little progress has been made since. This is possibly due to two reported cases of toxicity.

Forbes and Davies reported toxicology studies of a furano derivative (ICI 78911 [8]) that was in development for the treatment of Gram-negative infections. Toxicology studies in rodents yielded no abnormal findings. However, corneal ulceration in dogs was evident following administration of three daily doses of $25 \mathrm{mg} / \mathrm{kg}$ [18] and was cited as the reason to stop further development.

Grassberger et al. cautioned against the potential toxicity associated with this class and openly speculated that boron could be involved [14]. However, no toxicity data were published and no proof (or testable hypothesis) that boron was the origin of toxicity was offered. A retrospective on Grassberger's work then misinterpreted these comments as proof that boron cannot be used clinically because of the 'inherent toxicity of boron-containing compounds' [19].
This has had a most unfortunate consequence as subsequent articles have referenced this review propagating the notion that boron is toxic [19]. More recent studies [20-24] with other classes of diazaborines have not mentioned any reports of toxicity.

\section{Enoyl reductase is the target for \\ $\mathrm{N}$-sulfonyl diazaborines}

Enoyl reductase (ENR) is an enzyme involved in fatty acid biosynthesis. ENR is a target of a front-line anti-TB drug isoniazid and the antimicrobial agent triclosan [9]. $\mathrm{N}$-sulfonylsubstituted diazaborine inhibitors of ENR form a covalent $\mathrm{B}-\mathrm{O}$ ester with the 2-hydroxyl group of the cofactor nicotinamide adenosine ribose, forming an inhibitor-substrate adduct bound in the enzyme active site. Co-crystal structures for a variety of sulfonyldiazaborines have been published that explain the preference for the sulfonyl group and confirms boron is critical to the mechanism of inhibition [25]. In addition to accepting an intramolecular hydrogen bond from the boron hydroxyl group, the electronwithdrawing nature of the sulfonyl group stabilizes the negative charge on the boron atom and induces a conformational bend into the molecule that orients the sulfonyl substituent into a cavity of the active site.

\section{Diazaborines for TB}

Renewed interest in this area followed the publication of diazaborine's mechanism of action with evaluation of new classes of diazaborines including the isosteric 2,4,1-benzo [e] diazaborines, targeting Mycobacterium tuberculosis [24]. Comparisons were made with two front-line TB drugs: isoniazid and pyrazinamide.

While none of the diazaborines tested had activity near the potency of isoniazid, two derivatives $(9 \& 10)$ had MIC values in the range of $8-16 \mu \mathrm{g} / \mathrm{ml}$, which is superior to pyrazinamide $(\sim 200 \mu \mathrm{g} / \mathrm{ml})$.

\section{Diazaborines as steroid mimics}

Another potential application of diazaborines is in the design of 'ultra-high' fidelity estrogen structural mimics (II).

Crystalographic data for compound II, which contains an intramolecular hydrogen bond, confirm the estrogen-like conformation of these boron-containing heterocycles [23]. Screening for antiproliferative activity against MCF-7 human breast cancer cells demonstrated an $\mathrm{IC}_{50}$ value for II of approximately $5 \mu \mathrm{M}$ [9]. 


\section{- Boronic acid hepatitis $C$ virus serine protease inhibitors}

Hepatitis $\mathrm{C}$ virus (HCV) infection is a major cause of human liver disease. It is estimated that over 200 million people worldwide are chronically infected with HCV. HCV was first identified by molecular cloning in 1989 [26] and is an enveloped virus containing a single-strand RNA molecule of positive polarity with approximately 9600 base pairs. The HCV serine protease NS3/4A is considered to be an essential enzyme for the replication of the virus and has been a clinically validated drug target by BILN-2061 [27].

Peptide boronic acid derivatives, targeting the NS3/4A serine protease by trapping the catalytic Ser-139 hydroxyl functional group with its empty $p$-orbital of boron, have been investigated for more than a decade in the quest for novel agents for the treatment of HCV infection. The functional boronic acid is positioned at the peptide-1 (P1) position of the peptidomimetic. Compound $\mathbf{1 2}$ is an example of the class of peptide boronic acids discovered in 1996 and shows an $\mathrm{IC}_{50}$ of $34 \mathrm{nM}$ against the NS3/4A enzyme [201].

A less-polar analog, 13, was also made, presumably with the intention to improve cellular penetration. Afterwards, shorter peptide boronic acids and their esters with proline scaffold, such as 14, 15 and 16, were synthesized [202,203]. The (+)-pinanediol moiety is needed for the chiral synthesis of the P1 amino boronic acid and may also promote the cellular penetration due to its lipophilicity.

A follow-up study of 14 P1-variable analogs reveals that compound $\mathbf{1 7}$ has a Ki of $2 \mathrm{nM}$ against NS3 protease, 1000-fold selectivity over elastase and 40-fold selectivity over chymotrypsin [28].

The enzyme potency of $\mathbf{I} \mathbf{7}$ is remarkable. The large borate ester present at the P1 site might have been hydrolyzed to expose the functional boronic acid. More recent examples have quinoline and isoindoline structures at the $\mathrm{P} 2^{*}$ position. Examples include compounds $\mathbf{1 8}$ and $\mathbf{1 9}$, which have borate ester functionalities at the P1 site and quinoline and isoindoline at the $\mathrm{P} 2 *$ site, respectively. Both inhibitors exhibited increased molecular interaction with the NS3 protease, as reflected in their potency enhancement $[205,206]$. This also resulted in the lower peptide character of the inhibitors compared with previous compounds, such as $\mathbf{1 7}$, and is a progress towards the goal of discovering inhibitors for oral use.

A further advance in this area was the successful synthesis of macrocyclic boronic acid protease inhibitors, for example 20-22 [207]. Although the biological data have not been disclosed, their enzyme potencies are likely to be better than the corresponding acyclic analogs, as observed with other nonboronic acid protease inhibitors, due to the reduced rotational freedom and the known SAR in the HCV protease inhibitor field. It is speculated that one of their derivatives might have entered clinical development [107].

Schering-Plough scientists recently published their work on boronic acid derivatives of SCH-503034 (23). SCH-503034 is in advanced clinical development for the treatment of HCV [29].

As illustrated in the appendices, the replacement of P1 ethyl side chain in 24, 26 and $\mathbf{2 8}$ with cyclobutylmethyl improves enzyme potencies by 50-, 68- and 260-fold, respectively, giving $25(\mathrm{Ki}=10 \mathrm{nM}), 27(\mathrm{Ki}=0.5 \mathrm{nM})$ and 29 $(\mathrm{Ki}=0.2 \mathrm{nM})$. Enzyme potencies of boronic acids are not significantly different from their pinanediol esters in comparison of $\mathbf{2 6}$ with $\mathbf{2 8}$ and $\mathbf{2 7}$ with 29. Evaluation of these compounds in the cell-based replicon assay gave an $\mathrm{EC}_{90}$ of more than $5 \mu \mathrm{M}$. The poor potency suggests that these inhibitors may have very limited cell permeability.

In summary, incorporation of boronic acid into $\mathrm{HCV}$ serine protease inhibitors has been a successful strategy in finding novel HCV therapeutics.

\section{Boronic acid as $\beta$-lactamase inhibitors} $\beta$-lactam antibiotics remain the most used antibacterial agents in clinical practice. Their mechanism of action consists of interfering with cell wall assembly by binding to penicillin-binding proteins that insert the peptidoglycan precursors into the nascent cell wall and inhibiting bacterial growth [30]. However, the continuous development of resistance represents a serious threat to the clinical utility of $\beta$-lactams, leading to an urgent requirement for new compounds [31].

$\beta$-lactamases represent the most common single cause of bacterial resistance to $\beta$-lactam antibiotics, especially in Gram-negative bacteria [32] . $\beta$-lactamases act by catalyzing the hydrolysis of the amide bond of the $\beta$-lactam ring, thus leading to biologically inactive products [33]. There are more than 450 members of the $\beta$-lactamase superfamily, divided into four classes $(\mathrm{A}, \mathrm{B}, \mathrm{C}$ and D). Classes A, C and D are serine proteases and class $B$ is a metallo- $\beta$-lactamase. An important strategy that has been successfully utilized for overcoming $\beta$-lactamase-mediated resistance 
to $\beta$-lactams has been the co-administration of the $\beta$-lactam antibiotic together with a $\beta$-lactamase inhibitor [34]. In these combinations, the $\beta$-lactamase inhibitor forms a covalent adduct with the enzyme, preventing it from hydrolyzing the $\beta$-lactam antibiotic. Three widely spread clinical $\beta$-lactamase inhibitors, clavulanic acid, tazobactam and sulbactam, are effective only against class A serine $\beta$-lactamases [35]. Therefore, there is a clear medical need for broad-spectrum inhibitors that include activity against class $\mathrm{C}$ and $\mathrm{D}$ enzymes [36].

Boronic acid derivatives have proven to be promising selective inhibitors of the serine protease family of $\beta$-lactamases. The electrophilic boron atom acts as a mimic of the carbonyl carbon of the $\beta$-lactam ring and forms a tetrahedral adduct with the catalytic serine, which closely resembles one of the transition states of the hydrolytic mechanism [37]. Compounds 30-32 were discovered as potent inhibitors of AmpC $\beta$-lactamase. They were designed to gain interactions with highly conserved residues, such as Asn 343 , in addition to catalytic serine, and to bind more tightly to the enzymes. Compound 30 has a Ki value of $420 \mathrm{nM}$ in AmpC. The stereocontrolled introduction of the phenyl group, mimicking the dihydrothiazine ring as well as the configuration at the $\mathrm{C} 7$ of cephalosporins, led to a tenfold improvement in affinity (compound $3 \mathbf{I}, \mathrm{Ki}=35 \mathrm{nM}$ ). Addition of a $m$-carboxyphenyl moiety further improved affinity against AmpC $\beta$-lactamase (32, $\mathrm{Ki}=1 \mathrm{nM}$ ) [37].

Another series of glycylboronic acids bearing the side chains of cephalosporins and penicillins have proven to be reversible and competitive inhibitors of CTX-M $\beta$-lactamase. Compound 33, containing the side chain of nafcillin, has Ki values of 1.2 and $3.0 \mu \mathrm{M}$ against CTX-M-9 and CTX-M-16, respectively. The 2-aminothiazole inhibitor 34, containing the side chain from ceftazidime, has Ki values of 15 and $4 \mathrm{nM}$ against CTX-M-9 and CTX-M-16, respectively. Both $\mathbf{3 3}$ and $\mathbf{3 4}$ adopted a conformation in the active site consistent with acylation transition state analogues [38].

In summary, the unique ability of the boronic acid functionality to accept an active site serine into its electophilic $p$-orbtal has provided a novel series of $\beta$-lactamase inhibitors.

\section{Amino-acyl tRNA synthetase inhibitors}

There is a clear need to develop new efficacious therapeutics to treat fungal infections. One of the strategies is to discover and develop novel chemotype agents. Amino-acyl t-RNA synthetases are crucial for protein synthesis, and targeting the editing domain of this enzyme is a new approach to its inhibition. A new class of boroncontaining compounds, known as 1,3-dihydro-1hydroxy-2,1-benzoxaboroles, has been identified as inhibitors of fungal leucyl t-RNA synthetase and have potent antifungal activities with MICs as low as $0.25 \mu \mathrm{g} / \mathrm{ml}$ against the major dermatophytes Trichophyton rubrum and Trichophyton mentagrophytes and the yeasts and molds Candida albicans, Cryptococcus neoformans and Aspergillus fumigatus [39,208]. AN2690 (35) and AN2718 (36) are two examples of this class of compounds.

A penetration study indicated that these benzoxaborole compounds can effectively penetrate through human nail plate and reach the nail bed in sufficient concentration to inhibit fungal pathogens [40]. AN2690 (35) is currently in clinical development for the topical treatment of onychomycosis, a fungal infection of the nail and nail bed. AN2718 (36) is also in clinical trials to treat skin and other topical fungal infections.

Mechanism investigation with AN2690 (35) demonstrates that this compound inhibits yeast cytoplasmic leucyl-tRNA synthetase by formation of a stable AN2690-tRNA ${ }^{\text {Leu }}$ adduct (38) in the editing site of the enzyme [41]. The AN2690tRNA ${ }^{\text {Leu }}$ adduct (38) is formed through the boron atom of the AN2690 (35) and the cis-diol on the $3^{\prime}$-terminal adenosine (37) of the tRNA, as proposed below.

The trapping of enzyme-bound tRNA ${ }^{\text {Leu }}$ in the editing site prevents catalytic turnover, thus inhibiting synthesis of leucyl-tRNA ${ }^{\text {Leu }}$ and consequentially blocking protein synthesis. This result establishes the editing site as a novel target for aminoacyl-tRNA synthetase inhibitors.

In summary, the recent discovery of boron therapeutics as amino acyl t-RNA synthetase inhibitors, acting by trapping the tRNA in the enzyme-editing domain, is expected to be a promising field for the discovery of novel antifungal therapeutics. The combination of the unique boron chemistry, molecular-level knowledge gained from crystal structure studies and rational drug design has established a powerful drug-discovery machinery to feed the development pipeline.

\section{- Boron-containing anticoagulants}

Thrombin and Factor Xa have been promising targets for anticoagulant agents for more than a decade. A number of boro-Lys- and boroArg-based (boronic acid analogs of lysine and
OXABOROLE

$\mathrm{R}-\mathrm{B}(\mathrm{OH})-\mathrm{R}^{\prime}$, five-membered heterocyclic ring containing a boron, an oxygen and three carbon atoms 
arginine) thrombin inhibitors with nanomolar to picomolar potency have been identified $[8,9]$. Recently, a potent thrombin inhibitor TRI50c (39, $\mathrm{Ki}=10 \mathrm{nM})$ has been developed and is in clinical trials for the treatment of thrombosis $[209,210]$. It is formulated for either oral (Ca salt: TGN167) [102] or intravenous ( $\mathrm{Na}$ salt: TGN255) [103] administration.

In addition, phenylboronic acid derivatives, represented by $\mathbf{4 0}$, were reported as inhibitors of another serine protease in the blood coagulation cascade, Factor XIa (FXIa) [42]. While the potency of $\mathbf{4 0}$ is still in the micromolar range, it showed a nine- to 31-fold selectivity to FXIa over FXa and thrombin, respectively, and more than 140-fold over trypsin.

These examples further support the utility of boronic acids against a variety of serine proteases by making use of the ability of the boron to form a tetrahedral transition state mimic with the active site nucleophile.

\section{- Boron-containing dipeptidyl peptidase 4 inhibitors}

Dipeptidyl peptidase 4 (DPP4, also known as CD-26) is a serine protease that specifically removes Xaa-Pro dipeptides from the $\mathrm{N}$-terminus of polypeptides and proteins [43]. DPP4 is found in a variety of mammalian cells and tissues [44]. However, it was not recognized as an important drug target until 1995, when glucagon-like peptide-1 (GLP-1) was identified as one of the substrates of DPP4 [45,46]. GLP-1 stimulates glucose-induced insulin biosynthesis and secretion [47], and increasing blood GLP-1 concentration seemed to be a promising approach to treat diabetes. However, GLP-1 is rapidly inactivated by DPP4 in vivo and discovery of DPP4 inhibitors therefore became a promising concept for treatment of diabetes [48]. Indeed, the smallmolecule DPP4 inhibitor Januvia ${ }^{\circledR}$ (sitagliptin) was approved by the US FDA for the treatment of Type 2 diabetes [49].

Bachovchin et al. reported that peptide prolyl boronic acids are potent inhibitors of bacterial IgA1 proteinases [50]. They applied a similar strategy to design potent DPP4 inhibitors and, following extensive SAR, they identified AlaboroPro (4I) and Pro-boroPro (42) as very potent inhibitors of DPP4 (2 $\mathrm{nM}$ for $\mathbf{4 I}$ and $3 \mathrm{nM}$ for 42) [51,52]. The $\mathrm{NH}_{2}-\mathrm{P} 2$-boroP1 structure is the essential pharmacophore for the DPP4 inhibition. Simple boroPro (43) and N-Boc-AlaboroPro (44) were not active, while the $\mathrm{P} 2$ residue has some flexibility. As for the $\mathrm{P} 2$ residue, Ala, Glu, Gly and Pro showed nanomolar to picomolar Ki values. The boroPro moiety can be substituted with boroAla as well, although boroAla derivatives are less active than boroPro. There is a concern of selectivity to DPP4 over DPP8, DPP9 and potentially other enzymes for these boropeptides. It could be overcome by the structural modifications of the molecule [53]. Recently, in vivo blood glucose-lowering activity of compounds 4I, 45 and 46 (Glu-boroPro) was reported [54] and the safety of these three closely related dipeptide boronic acid inhibitors (4I, 45 \& 46) was determined. Just like the nonboron inhibitors of the DPP4 enzyme, their toxicity is related to their inhibition of related isozymes DPP8 and DPP9. A tight correlation was observed between intracellular inhibition of DPP9 and the maximum tolerated dose (MTD) (TABLE I). The GluboroAla (46) is a selective inhibitor of DPP4, and it is a safe compound, while the toxicity of the other compounds is related to their nonselective nature (TABLE I). Therefore, the author concluded that boronic acid-based inhibitors of DPP4 do not exhibit unique or untoward toxicities. While Val-boroPro (45, talabostat) is a potent DPP4 inhibitor [52], this compound is also in clinical trials for colorectal cancer as a fibroblast activation protein (FAP) inhibitor [54].

Very recently, clinical trial results of GlyboroPro derivative DPP4 inhibitor PHX1149 (47) were reported [55-57,104]. PHX1149 was given orally at the doses of 200 or $400 \mathrm{mg}$. Patients were allowed to continue either metformin or thiazolidinedion, or a combination of the two. PHX1149 showed statistically significant reductions on hemoglobin Alc (HbAlc) in both 200and 400-mg groups. PHX1149 also demonstrated

\section{Table 1. Boronic acid-based dipeptidyl peptidase 4 inhibitors*.}

\begin{tabular}{llllll} 
Compound & KI $^{\text {DPP4 }}$ & KI $^{\text {DPP8 }}$ & KI $^{\text {DPP9 }}$ & IC $^{\text {DPP9 }}$ IC $_{\mathbf{5 0}}(\boldsymbol{\mu M})$ & MTD $(\mathbf{m g} / \mathbf{k g})$ \\
\hline Val-boroPro (45) & 0.18 & 1.5 & 0.76 & 6.8 & 0.025 \\
\hline Ala-boroPro (4I) & 0.027 & 2.0 & 0.53 & 360 & $5.0 \leqslant$ MTD $<38$ \\
Glu-boroAla (46) & 8.3 & 880 & 2100 & 7000 & $500 \leqslant$ MTD $<900$
\end{tabular}

${ }^{*} \mathrm{Kl}$ is in $\mathrm{nM}$

DDP: Dipeptidyl peptidase; MTD: Maximum-tolerated dose. 
statistically significant efficacy on the secondary end point including change in fasting and postmeal blood glucose levels. There was no substantial difference observed between active arms and placebo in terms of safety and tolerability.

In summary, boronic acid inhibitors of DPP4 have made a substantial contribution to this important field.

\section{- Boron-containing} phosphodiesterase 4 inhibitors

Phosphodiesterases (PDEs) are a family of enzymes responsible for the hydrolysis of second-messenger cAMP and cGMP [58]. The PDE superfamily comprises at least 11 members, including approximately 100 isoforms $[59,60]$. Among those, PDE 4 specifically catalyzes the hydrolysis of cAMP and is the predominant phosphodiesterase enzyme in immune and inflammatory cells [61,62]. Therefore, PDE4 has been considered as a promising therapeutic target and a number of inhibitors have entered clinical trials for the treatment of chronic obstructive pulmonary disease, asthma, various kinds of arthritis, inflammatory bowel disease, psoriasis and atopic dermatitis. Indeed, positive results from clinical trials of PDE4 inhibitors give the validation to the target [63]. Several drug candidates are close to filing for approval.

Of the thousands of publications on PDE inhibitors, no boronic acid inhibitors had been reported until recently, when a phenoxybenzoxaborole derivative, AN2728 (48), was reported to be a PDE4 inhibitor $\left(\mathrm{IC}_{50}=0.49 \mu \mathrm{M}\right)$ [64]. This compound shows anti-inflammatory activity and has a structure distinct from existing PDE4 inhibitors. AN2728 (48) inhibits not only PDE 4 but also PDE1A3 $\left(\mathrm{IC}_{50}=6.1 \mu \mathrm{M}\right)$, PDE3 $\left(\mathrm{IC}_{50}=6.4 \mu \mathrm{M}\right)$ and PDE7A1 $\left(\mathrm{IC}_{50}=0.73 \mu \mathrm{M}\right)$. AN2728 is currently under Phase II clinical trial for the topical treatment of psoriasis [64], and is showing positive results [105].

In summary, the versatility shown by boron for different modes of inhibition has provided a novel therapeutic lead for PDE4.

\section{Boron compounds entered into clinical trials}

Among the first boron-containing compounds approved for human use is paraboronophenylalanine for boron NCT. Because of the unique composition, this compound is preferentially taken up by tumor cells through their L-amino acid transporter. This compound is an important component of neutron capture therapy and it is safe when used in doses of up to $900 \mathrm{mg} / \mathrm{kg}$ in humans [5]. Approval of Velcade (49) by the FDA as an anticancer agent in 2003 [106] has assured pharmaceutical developers that boron is a druggable element. There are numerous boron compounds that have entered various stages of clinical development.

Januvia $^{\circledR}$ is a selective DPP4 inhibitor approved by the FDA for the treatment of Type II diabetes. Dipeptide mimetics contain boroPro and are potent DPP4 inhibitors. They have the potential to be antidiabetic agents. PHX1149 (dutogliptin, 47) is a low-molecular-weight, highly watersoluble, orally bioavailable selective DPP4 inhibitor, currently in Phase III clinical trials [107]. In Phase I and II trials, PHX1149 was well tolerated up to $400 \mathrm{mg}$. The drug has a long half-life of $10-13 \mathrm{~h}$ and is well absorbed in humans.

Talabostat (PT100, 45) is a Val-boroPro DPP4 inhibitor and also inhibits the FAP. It entered Phase III clinical trials for non-smallcell lung cancer as a component of a drug combination [108]. The trials are currently on hold due to lack of efficacy. In the Phase I clinical trial, the drug is well tolerated at single doses of less than $600 \mu \mathrm{g}$, and it is well absorbed achieving peak plasma levels within $0.9-2 \mathrm{~h}$ [57].

Other boron-containing compounds under clinical evaluation already discussed in this review include AN2690 (35), which has completed Phase II clinical trials for the treatment of onychomycosis, AN2718 (36), which has completed Phase I clinical trials for the treatment of skin and nail fungal infections, TRI50c (TGN167 and TGN226) (39) from Trigen, currently in Phase III clinical trials as an anticoagulant, AN2728 (48), currently in Phase II clinical trials for the treatment of psoriasis, and AN0128 (50), currently in Phase II clinical trials for the treatment of periodontal disease and acne [65].

Phenomix Pharmaceuticals has a HCV protease inhibitor entered into clinical development, and it is reasonable to speculate that it might be a boron compound judging by recent patent publications [205-207].

\section{Future perspective}

Relative to carbon, hydrogen, nitrogen and oxygen, we are still learning the benefits of boron in therapeutics, and there are also very few boroncontaining natural products identified to date to serve as leads for medicinal chemists. There is a lot of skepticism regarding the use of boron by the medicinal chemistry community due to perceived toxicity concerns and, therefore, 
boron has been long overlooked as an element to include in small-molecule therapies. Companies such as Millennium Pharmaceuticals, Point Therapeutics and Anacor Pharmaceuticals are currently pioneering the field of boron therapeutics and discovering the many benefits of boron. As such, we now find more boron-containing therapies currently in clinical trials and the industry is beginning to pay much desired attention to this promising class.

Over the next 5 years, we will see the results of the compounds currently in clinical trials, as well as more boron-containing compounds entering clinical trials. By this time, the medicinal chemistry community may be likely to be more accepting of the concept of using boron, coinciding with more knowledge of chemical processes to handle and manipulate boroncontaining small molecules from pioneering research being conducted by the academic community. This will give rise to a new generation of medicinal chemists familiar with boron chemistry and more willing to include it in their designs. In 10 years time, boron may become commonplace in drug-discovery research, with several boron therapeutics moving through research and clinical pipelines and more boroncontaining therapeutics on the market.
As previously mentioned, the physical, chemical and biological properties of boron offer medicinal chemists a rare opportunity to explore and pioneer new areas of drug discovery. We think that, once the current biased response dismissing boron dissipates, boron could become widely accepted as a useful atom in future medicines.

\section{Acknowledgements}

The authors would like to thank Conrad Wheeler for the data on boron concentrations in plasma. The authors would also like to thank Jacob Plattner, Kirk Maples, Karin Hold, Dickon Alley, Yvonne Freund, Sanjay Chanda and David Perry for their kind review of this manuscript.

\section{Financial \& competing interests disclosure}

The authors are all current employees of Anacor Pharmaceuticals Inc. The authors have no other relevant affliations or financial involvement with any organization or entity with a financial interest in or financial conflict with the subject matter or materials discussed in the manuscript. This includes employment, consultancies, honoraria, stock ownership or options, expert testimony, grants or patents received or pending, or royalties.

No writing assistance was utilized in the production of this manuscript.

\section{Executive summary}

- The element boron has long been overlooked for use in chemotherapeutics, possibly due to a perceived risk of toxicity.

- The overwhelming data for the safety of boron should be noted; we consume in the range of $0.3-4.2 \mathrm{mg}$ of boron per day and it is considered an essential plant nutrient. Boric acid has a similar $\mathrm{LD}_{50}$ to regular table salt.

- The physical, chemical and biological properties of boron offer medicinal chemists a rare opportunity to explore and pioneer its utility in chemotherapeutics.

- Boron has an empty p-orbital that can accept biological nucleophiles to form strong interactions and increase the affinity of the chemotherapeutic with its target.

- Boron-containing therapeutics already target several different biological receptors, with different mechanisms of interaction.

- Currently, there is one boron-containing therapeutic agent on the market and several in various stages of clinical trials.

- As more is discovered about the chemistry and biology of boron, and more is learned from compounds in current clinical trials, boron could become widely accepted as a useful atom in future medicines.

\section{Bibliography}

Papers of special note have been highlighted as:

- of interest

"- of considerable interest

1 Julian Adams. Protein homeostasis in cancer. Presented at: ACS ProSpectives: the discovery and selection of successful drug candidates. Boston, MA, USA, 29 April-2 May 2007.

2 Rainey CJ, Nyquist LA, Christensen RE, Strong PL, Culver BD, Coughlin JR. Daily boron intake from the American diet. J. Am. Diet Assoc. 99(3), 335-340 (1999).
3 Pekol T, Daniels JS, Labutti J et al. Human metabolism of the proteasome inhibitor bortezomib: identification of circulating metabolites. Drug Met. Disp. 33(6), 771-777 (2005).

4 Taniyama K, Fujiwara H, Kuno T et al. Acute and subacute toxicity of 10B-paraboronophenylalanine. Pigment Cell Res. 2, 291-296 (1989).

5 Henriksson R, Capala J, Michanek A et al. Boron neutron capture therapy (BNCT) for glioblastoma multiforme: a Phase II study evaluating a prolonged high-dose of boronophenylalanine (BPA). Radiother. Oncol. 88, 183-191 (2008).

6 Hideghety K, Sauerwein W, Wittig A et al. Tissue uptake of $\mathrm{BSH}$ in patients with glioblastoma in the EORTC 11961 Phase I BNCT trial. J. Neuro. Oncol. 62, 145-156 (2003).

7 Hall DG. Boronic acids. Preparation, Applications in Organic Synthesis and Medicine. Wiley-VCH Verlag GmbH \& Co., Weinheim, Germany (2005). 
- Comprehensive overview of boronic acids.

8 Yang W, Gao X, Wang B. Boronic acid compounds as potential pharmaceutical agents. Med. Res. Rev. 23(3), 346-368 (2003).

- Valuable review of boronic acids in medicine.

9 Groziak MP. Boron therapeutics on the horizon. Am. J. Ther. 8, 321-328 (2001).

- Valuable review of boron therapeutics.

10 Barth RF, Coderre JA, Vicente MG, Blue TE. Boron neutron capture therapy of cancer: current status and future prospects. Clin. Cancer Res. 11(11), 3987-4002 (2005).

11 Dewar MJS. Progress in Boron Chemistry (Volume 1). Steinberg H, McCloskey AL (Eds). Macmillan, NY, USA (1964).

12 Gronowitz S, Dahlgren T, Namtvedt J et al. Antibacterial borazaro derivatives. I. 5-arylsulfonyl-4-hydroxy-4,5borazarothieno[2,3-c]pyridines and 6-arylsulfonyl-7-hydroxy-7,6borazarothieno [3,2-c]pyridines. Acta Pharmaceutica Suecica 8(4), 377-390 (1971).

13 Gronowitz S, Dahlgren T, Namtvedt J et al. Antibacterial borazaro derivatives. II. Effect of substituents on the antibacterial activity of 5-arylsulfonyl-4-hydroxy-4,5borazarothieno[2,3-c]pyridines and 6-arylsulfonyl-7-hydroxy-7,6borazarothieno [3,2-c] pyridines. Acta Pharmaceutica Suecica 8(6), 623-638 (1971).

14 Grassberger MA, Turnowsky F, Hildebrandt J. Preparation and antibacterial activities of new 1,2,3-diazaborine derivatives and analogues. J. Med. Chem. 27, 947-953 (1984).

15 Högenauer G, Woisetschlaeger M. A diazaborine derivative inhibits lipopolysaccharide biosynthesis. Nature 293, 662-664 (1981).

16 Baldock C, Rafferty JB, Sedelnikova SE et al. A mechanism of drug action revealed by structural studies of enoyl reductase. Science 274, 2107-2110 (1996).

17 Baldock C, Rafferty JB, Sedelnikova SE et al. Crystallization of Escherichia coli enoyl reductase and its complex with diazaborine. Acta Crystallogr D52, 1181-1184 (1996).

18 Forbes D, Davies G. Antibacterial activity of ICI 78,911 and a metabolite, ICI 79,489. Curr. Chemother. Proc. Int. Congr. Chemother. 10(1), 572-574 (1978).

19 Baldock C, de Boer GJ, Rafferty JB et al. Mechanism of action of diazaborines. Biochem. Pharmacol. 55, 1541-1549 (1998).

20 Groziak MP, Ganguly AD, Robinson PD. Boron heterocycles bearing a peripheral resemblance to naturally occurring purines: design, syntheses, structures, and properties. J. Am. Chem. Soc. 116, 7597-7605 (1994).

21 Groziak MP, Chen L, Yi L et al. Planar boron heterocycles with nucleic acid-like hydrogenbonding motifs. J. Am. Chem. Soc. 119, 7817-7826 (1997).

22 Robinson PD, Groziak MP, Chen L. A 2-alkyl substituted 2,3,1-benzodiazaborine. Acta Crystallogr. C54, 71-73 (1998).

23 Robinson PD, Groziak MP. A boroncontaining estrogen mimic. Acta Crystallogr. C55, 1701-1704 (1999).

24 Davis MC, Franzblau SG, Martin AR. Syntheses and evaluation of benzodiazaborine compounds against M.tuberculosis $\mathrm{H} 37 \mathrm{RV}$ in vitro. Bioorg. Med. Chem. Lett. 8, 843-846 (1998).

25 Levy CW, Baldock C, Wallace AJ et al. A study of the structure-activity relationship for diazaborin inhibition of Escherichia coli enoyl-ACP reductase. J. Mol. Biol. 309, 171-180 (2001).

26 Choo QL, Kuo G, Weiner AJ. Isolation of a cDNA derived from a blood-borne non-A non-B viral hepatitis genome. Science 244 , 359-362 (1989).

27 Llinàs-Brunet $\mathrm{M}$, Bailey $\mathrm{MD}$, Bolger $\mathrm{G}$ et al. Structure-activity study on a novel series of macrocyclic inhibitors of the hepatitis $\mathrm{C}$ virus NS3 protease leading to the discovery of BILN 2061. J. Med. Chem. 47(7), 1605-1608 (2004).

28 Priestley ES, Lucca ID, Ghavimi B, EricksonViitanen S, Decicco CP. P1 phenethyl peptide boronic acid inhibitors of HCV NS3 protease. Bioorg. Med. Chem. Let. 12(21), 3199-3202 (2002).

29 Venkatraman S, Wu W, Prongay A, Girijavallabhan V, Njoroge FG. Potent inhibitors of HCV-NS3 protease derived from boronic acids. Bioorg. Med. Chem. Lett. 19(1), 180-183 (2009).

30 Goffin C, Ghuysen JM. Multimodular penicillin-binding proteins: an enigmatic family of orthologs and paralogs. Microbiol. Mol. Bio. Rev. 62, 1079-1093 (1998).

31 Bassetti M, Righi E, Viscoli C. Novel $\beta$-lactam antibiotics and inhibitor combinations. Expert Opin. Investig. Drugs 17(3), 285-296 (2008).

32 Neu HC. The crisis in antibiotic resistance. Science 257, 1064-1073 (1992).

33 Livermore DM. $\beta$-lactamase-mediated resistance and opportunities for its control. J. Antimicrob. Chemother. 41, 25-41 (1998).

34 Bush K, Jacoby GA, Medeiros AA. A functional classification scheme for $\beta$-lactamse and its correlation with molecular structure. Antimicrob. Agents Chemother. 39, 1211-1233 (1995).
35 Miller LA, Ratnam K, Payne DJ. $\beta$-lactamase - inhibitor combinations in the 21st Century: current agents and new developments. Curr. Opin. Pharmacol. 1, 451-458 (2001).

36 Mansour TS, Bradford PA, Venkatesan AM. Recent developments in $\beta$-lactamases and inhibitors. Ann. Rep. Med. Chem. 43, 247-267 (2008).

37 Morandi S, Morandi F, Caselli E, Shoichet B, Prati F. Structure-based optimization of cephalothin-analogue boronic acids as $\beta$-lactamase inhibitors. Bioorg. Med. Chem. 16, 1195-1205 (2008).

38 Chen Y, Shoichet B, Bonnet R. Structure, function, and inhibition along the reaction corordinate of CTX-M $\beta$-lactamase. J. Am. Chem. Soc. 127, 5423-5434 (2005).

39 Baker SJ, Zhang Y-K, Akama T et al. Discovery of a new boron-containing anti-fungal agent, 5-fluoro-1,3-dihydro-1hydroxy-2,1-benzoxaborole (AN2690), for the potential treatment of onychomycosis. J. Med. Chem. 49(15), 4447-4450 (2006).

40 Hui X, Baker SJ, Wester RC et al. In vitro penetration of a novel oxaborole antifungal (AN2690) into the human nail plate. J. Pharm. Sci. 96(10), 2622-2631 (2007).

41 Rock FL, Mao W, Yaremchuk A et al. An antifungal agent inhibits an aminoacyltRNA synthetase by trapping tRNA in the editing site. Science 316, 1759-1761 (2007).

42 Lazarova TI, Jin L, RynKiewics M et al. Synthesis and in vitro biological evaluation of aryl boronic acids as potential inhibitors of factor Xia. Bioorg. Med. Chem. Lett. 16, 5022-5027 (2006).

43 Heins J, Welker P, Schönlein C et al. Mechanism of proline-specific proteinases: 1 substrate specificity of dipeptidyl peptidase IV from pig Kidney and proline-endopeptidase from Flavobacterium meningosepticum. Biochim. Biophys. Acta 954(2), 161-169 (1988).

44 Gossrau R. Cytochemistry of membrane proteases. Histochem. J. 17(7), 737-771 (1985).

45 Kieffer TJ, Mcintosh CHS, Pederson RA. Degradation of glucose-dependent insulinotoropic polypeptide and truncated glucagons-like peptidase 1 in vitro and in vivo by dipeptidyl peptidase IV. Endocrinology 136(8), 3585-3596 (1995).

46 Pauly RP, Rosche F, Wermann M et al. Investigation of glucose-dependent insulinotropic polypeptide-(1-42) and glucagons-like peptide-1-(7-36) degradation in vitro by dipeptidyl peptidase IV using matrix-assisted laser desorption/ionizationtime of flight mass spectrometry. J. Biol. Chem. 271(38), 23222-23229 (1996). 
47 Holst JJ. Enteroglucagon. Ann. Rev. Physiol. 59, 257-271 (1997).

48 Deacon CF, Hughes TE, Hoist JH. Dipeptidyl peptidase IV inhibition potentiates the insulinotropic effect of glucagons-like peptide 1 in the anesthetized pig. Diabetes 47, 764-769 (1998).

49 Gellwitz B. Sitagliptin: profile of a novel DPP-4 inhibitor for the treatment of Type 2 diabetes (update). Drugs Today 43(11), 801-814 (2007).

50 Bachovchin WW, Plaut AG, Flentke GR et al. Inhibition of IgA1 proteinases from Neisseria gonorrhoeae and Hemophilus influenzae by peptide prolyl boronic acids. J. Biol. Chem. 265(7), 3738-3743 (1990).

51 Flentke GR, Munoz E, Huber BT et al. Inhibition of dipeptidyl aminopeptidase IV (DP-IV) by Xaa-boroPro dipeptides and use of these inhibitors to examine the role of DP-IV in T-cell function. Proc. Natl Acad. Sci. USA 88, 1556-1559 (1991).

52 Coutts SJ, Kelly TA, Snow RJ et al. Structure-activity relationships of boronic acid inhibitors of dipeptidyl peptidase IV. 1 Variation of the P2 position of Xaa-boroPro dipeptides. J. Med. Chem. 39, 2087-2094 (1996)

53 Connolly BA, Sanford DG, Chiluwal AK et al. Dipeptidyl boronic acid inhibitors of dipeptidyl peptidase IV: determination of potency and in vivo efficacy and safety. J. Med. Chem. 51, 6005-6013 (2008).

54 Narra K, Mullins SR, Lee H-O et al. Phase II trial of single agent Val-boroPro (talabostat) inhibiting fibroblast activation protein in patients with metastatic colorectal cancer. Cancer Biol. Ther. 6(11), 1691-1699 (2007).

55 Garcia-Soria G, Gonzalez-Galvez G, Argoud GM et al. The dipeptidyl peptidase-4 inhibitor PHX1149 improves blood glucose control in patients with Type 2 diabetes mellitus. Diabetes Obes. Metab. 10(4), 293-300 (2008).

56 Gupta R, Walunj S, Tokala RK et al. Emerging drug candidates of dipeptidyl peptidase IV (DPP IV) inhibitor class for the treatment of Type 2 diabetes. Curr. Drug Targets 10(1), 71-87 (2009).

57 O'Farrell AM, Van VA, Farha KA et al. PharmacoKinetic and pharmacodynamic assessments of the dipeptidyl peptidase- 4 inhibitor PHX1149 : double-blind, placebo-controlled, single- and multipledose studies in healthy subjects. Clin. Ther. 29(8), 1692-1705 (2007).

58 Antoni FA. Molecular diversity of cyclic AMP signaling. Front. Neuroendocrinol. 21(2), 103-132 (2000).

59 Beavo JA. Cyclic nucleotide phosphodiesterases: functional implications of multiple isoforms. Physiol. Rev. 75(4), 725-748 (1995).

60 Bender AT, Beavo JA. Cyclic nucleotide phosphodiesterases: molecular recognition to clinical use. Pharmacol. Rev. 58, 488-520 (2006).

61 Torphy TJ, Undem BJ. Phosphodiesterase inhibitors: new opportunities for the treatment of asthma. Thorax 46(7), 512-523 (1991).

62 Fleming YM, Frame MC, Houslay MD. PDE4-regulated cAMP degradation controls the assembly of integrin-dependent action adhesion structures and REF52 cell migration. J. Cell Sci. 117(11), 2377-2388 (2004).

63 Dastidar SG, Rajagopal D, Ray A Therapeutic benefit of PDE 4 inhibitors in inflammatory diseases. Curr. Opin. Invest. Drugs 8(5), 364-372 (2007).

64 Akama T, Baker SJ, Zhang Y-K et al. Discovery and structure-activity study of a novel benzoxaborole anti-inflammatory agent (AN2728) for the topical treatment of psoriasis and atopic dermatitis. Bioorg. Med. Chem. Lett. 19, 2129-2132 (2009).

65 Baker SJ, Akama T, Zhang Y-K et al. Identification of a novel boron-containing antibacterial agent (AN0128) with anti-inflammatory activity, for the potential treatment of cutaneous diseases. Bioorg. Med. Chem. Lett. 16, 5963-5967 (2006).

\section{- Websites}

101 Material Safety Data Sheets available from Sigma-Aldrich www.sial.com

102 Combe S, Allen G, Kennedy A. A Phase I double-blind, ascending dose study of an oral synthetic direct thrombin inhibitor, TGN167. Blood 106, 1863 (2005) http://abstracts.hematologylibrary.org/cgi/ content/abstract/106/11/1863
103 Trigen opens IND for the initiation of a Phase III programme for flovagatran (formerly TGN 255), its novel intravenous direct thrombin inhibitor (DTI). BNET Business Publications, February 2007 http://findarticles.com/p/articles/mi_pwwi/ is_200702/ai_n17169523

104 Phenomix announces PHX1149 Phase 2b clinical trial results for Type 2 Diabetes. Medical News Today, May 2008 www.medicalnewstoday.com/articles/ 107950.php

105 Anacor announces positive results from Phase 2 psoriasis trial. Anacor Press Release, February 2009

www.anacor.com/press release_2009-2002-2019.php

106 Drug details on Velcade from Drugs@FDA www.accessdata.fda.gov/scripts/cder/ drugsatfda/index.cfm?fuseaction= search.DrugDetails

107 Phenomix announces Phx1149 Phase 2b Clinical trial results for Type 2 Diabetes. Phenomix press release, May 2008 www.phenomix.com/news-08-05-16.asp

108 Update on Point Therapeutics Merger with DARA BioSciences. DARA Press release February 2008 http://phx.corporate-ir.net/phoenix. zhtml? $\mathrm{c}=219408 \& \mathrm{p}=$ irol-newsArticle $\& I D=1$ 106638 \&highlight $=$ Talabostat

\section{- Patents}

201 F Hoffmann-La Roche AG WO98022496 (1998).

202 Du Pont Pharmaceuticals Company: WO2001002424 (2001).

203 Bristol-Myers Squibb Pharma Company: WO2001007407 (2001).

204 Bristol-Myers Squibb Pharma Company: WO2001064678 (2001).

205 Phenomix Corporation: WO2007016476 (2007).

206 Phenomix Corporation: WO2007089618 (2007).

207 Phenomix Corporation: WO2008070733 (2008).

208 Anacor Pharmaceuticals, Inc.: WO2007078340 (2007).

209 Trigen Limited: US20080234228 (2008). 210 Trigen Limited: US20080287370 (2008). 


\section{Appendix}

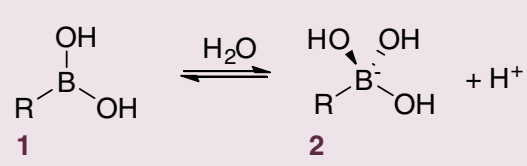<smiles>CS(=O)(=O)N1N=Cc2sccc2B1O</smiles>

5<smiles>CCCS(=O)(=O)N1N=Cc2sccc2B1O</smiles>

6<smiles>O=C1CN(/N=C/c2ccc([N+](=O)[O-])o2)C(=O)N1</smiles>

3 (nitrofurantoin)<smiles>CCCS(=O)(=O)N1N=Cc2sc(C)cc2B1O</smiles><smiles>CN1N=Cc2sc([N+](=O)[O-])cc2B1O</smiles>

4<smiles>O=S(=O)(c1ccccc1)N1N=Cc2occc2B1O</smiles>

8<smiles>O=C1Nc2ccccc2B(O)N1c1ccccc1</smiles>

9<smiles>OB1c2ccccc2NC(=S)N1c1cccnc1</smiles>

10<smiles>COc1cccc(N2N=Cc3cc(O)ccc3B2O)n1</smiles>

11<smiles>C=CCC(NC(=O)[C@H](CC(C)C)NC(=O)[C@H](NC(=O)[C@H](Cc1ccccc1C)NC(=O)[C@H](CCC(=O)O)NC(=O)[C@H](CC(=O)O)NC(=O)CCC(=O)O)C(C)(C)C)B(O)O</smiles>

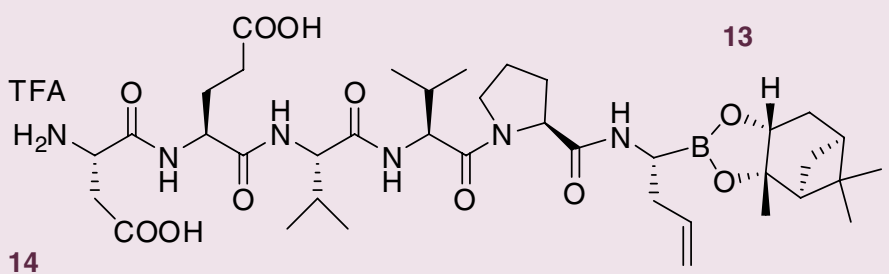

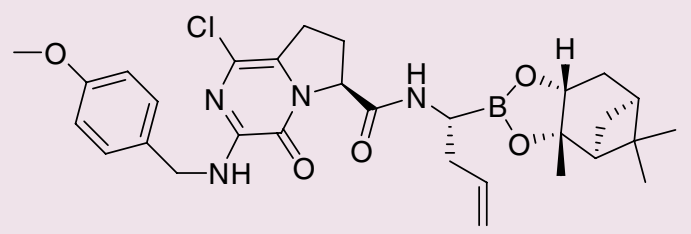

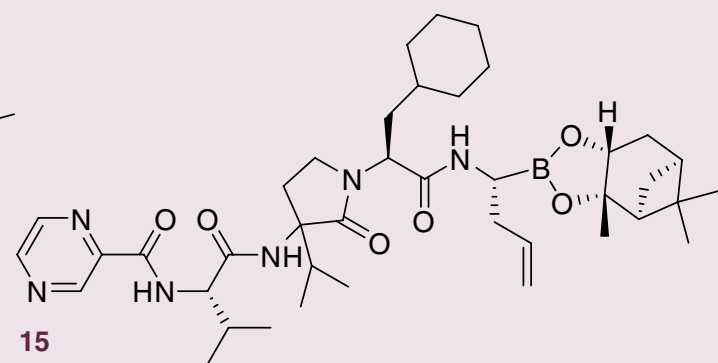

16

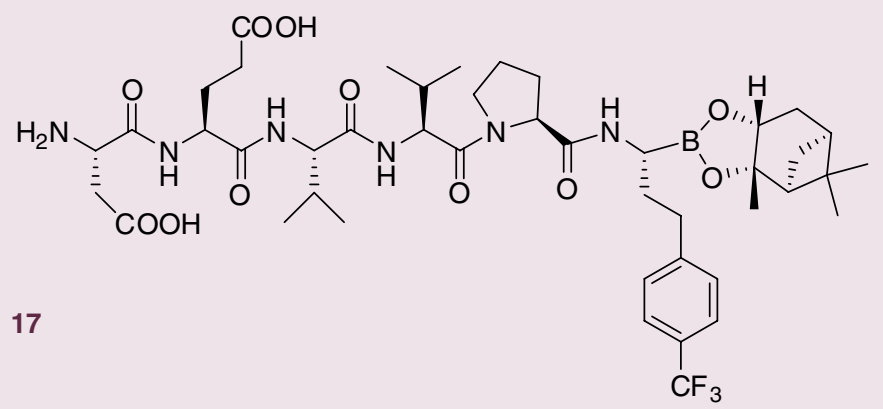



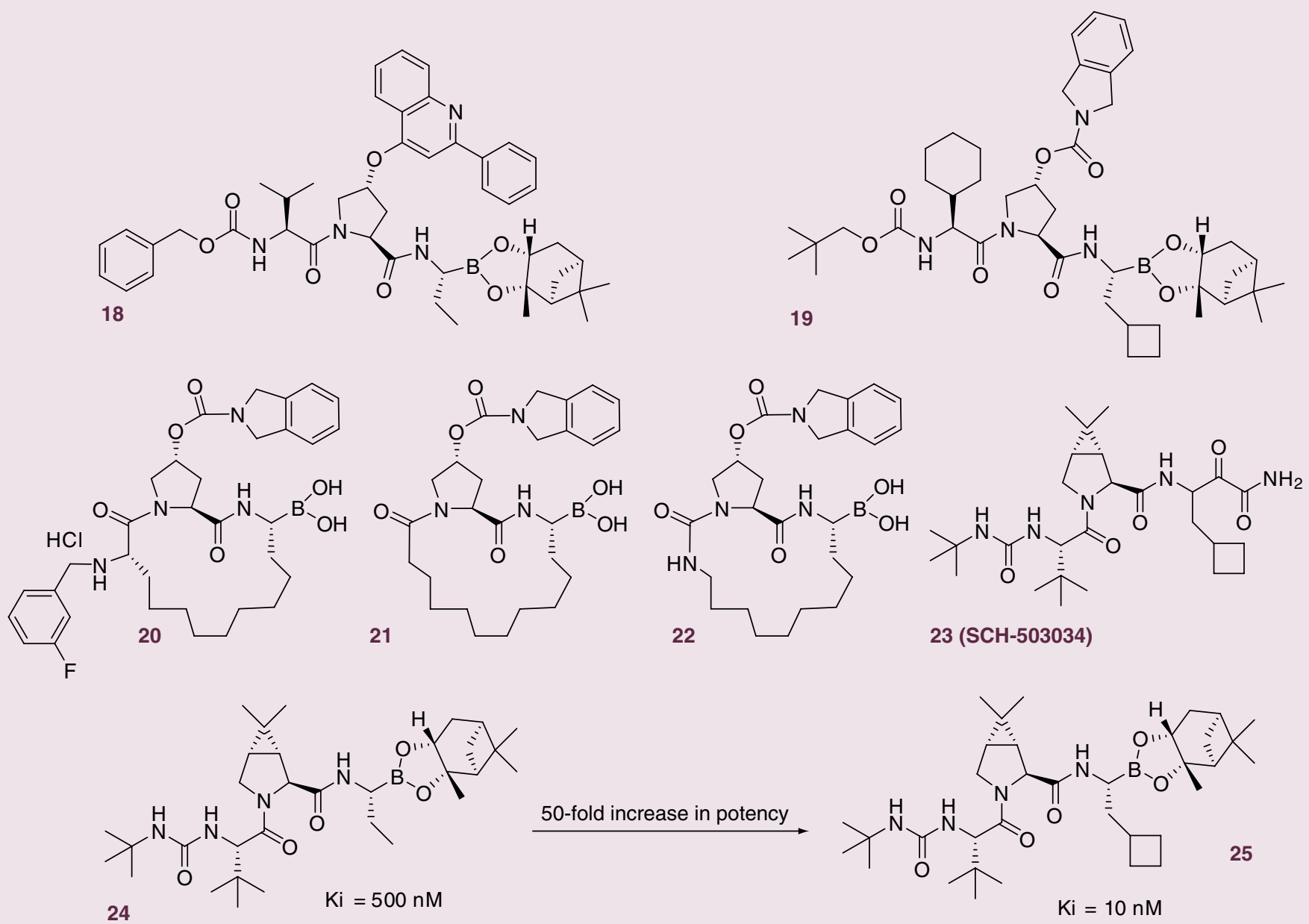

15-fold increase

20-fold increase

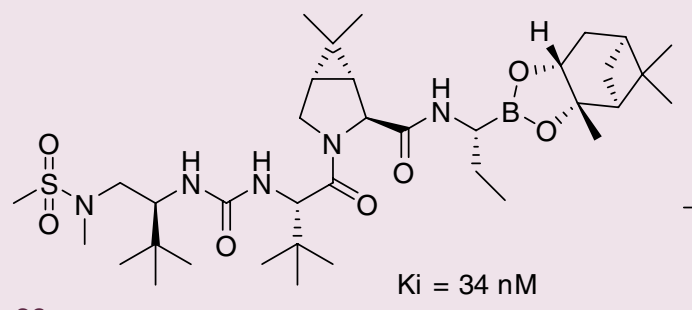

26
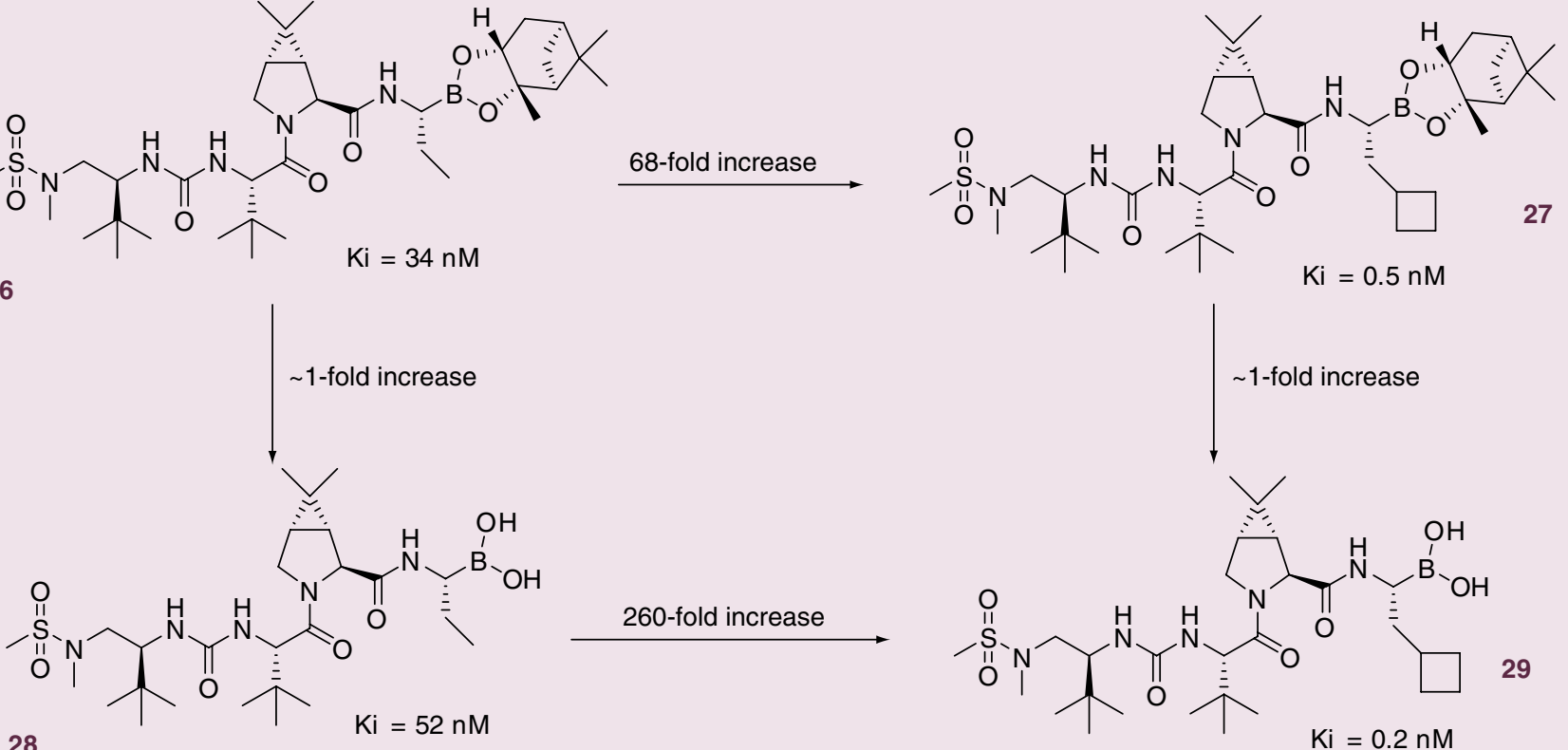

260-fold increase

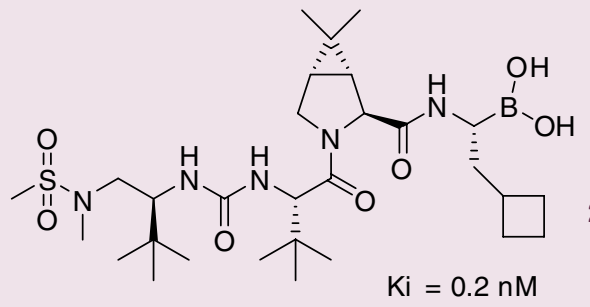




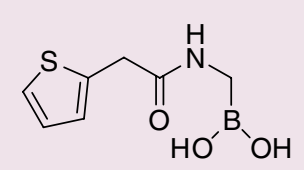

30<smiles>O=C(Cc1cccs1)N[C@@H](B(O)O)c1ccccc1</smiles>

31<smiles>O=C(Cc1cccs1)N[C@H](B(O)O)c1cccc(C(=O)O)c1</smiles><smiles>CCOc1ccc2ccccc2c1C(=O)NCB(O)O</smiles>

33<smiles>CC(C)(O/N=C(\C(=O)NCB(O)O)c1csc(N)n1)C(=O)[O-]</smiles>

34

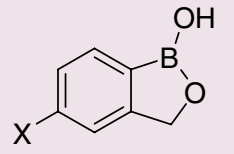

$35 X=F($ AN2690) $36 \mathrm{X}=\mathrm{Cl}(\mathrm{AN} 2718)$<smiles>Nc1ncnc2c1ncn2[C@@H]1O[C@H](COP(=O)([O-])O[Al])[C@@H](O)[C@H]1O</smiles>

37 (A76 of tRNA $\left.{ }^{\text {Leu }}\right)$<smiles>OB1OCc2cc(F)ccc21</smiles>

35 (AN2690)

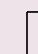<smiles>COCCC[C@H](NC(=O)[C@@H]1CCCN1C(=O)[C@H](Cc1ccccc1)NC(=O)OCc1ccccc1)C(=O)O</smiles>

39 (TRI50c)
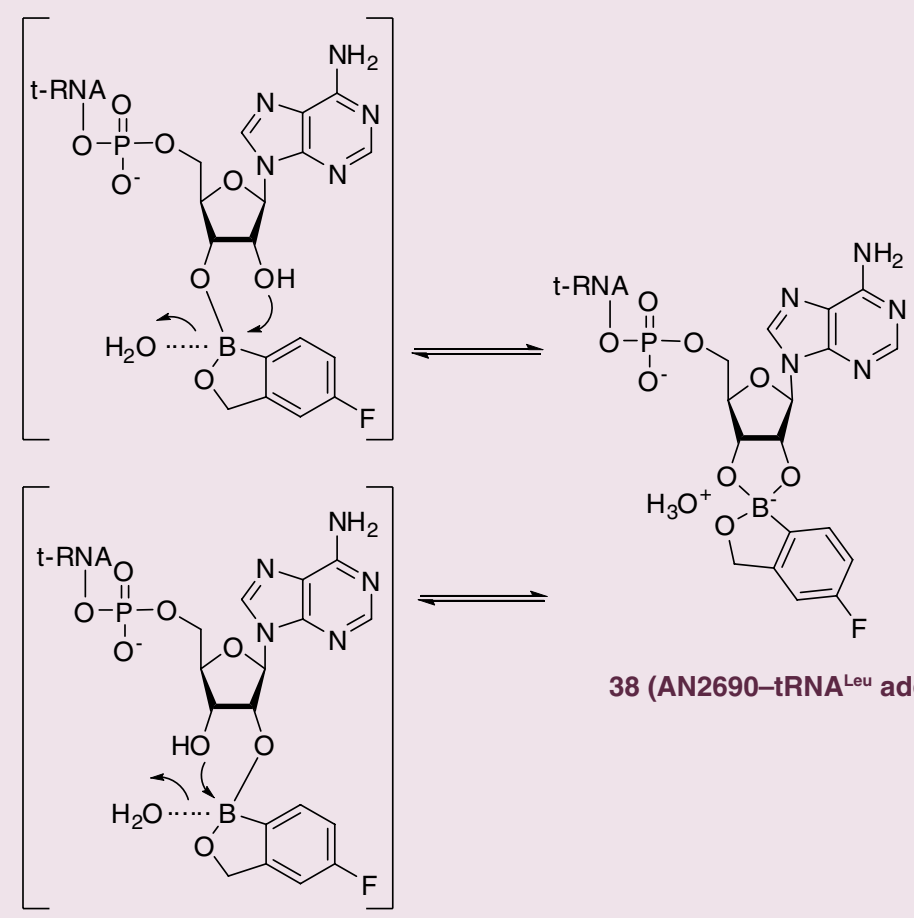

38 (AN2690-tRNA ${ }^{\text {Leu }}$ adduct)

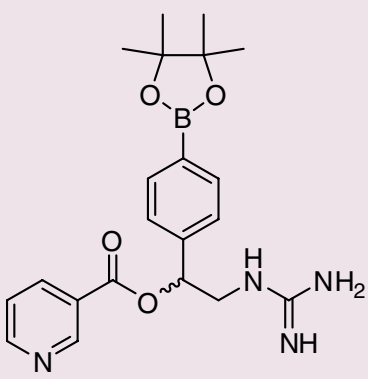

40 
<smiles>CC(NCl)C(=O)N1CCCC1B(O)O</smiles>

41

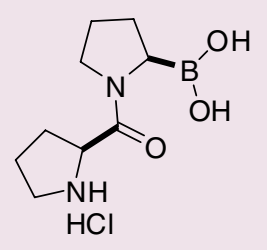

42<smiles>OB(O)C1CCCN1</smiles>

43<smiles>CC(NC(=O)OC(C)(C)C)C(=O)N1CCCC1B(O)O</smiles>

44<smiles>CC(C)C(N)C(=O)N1CCCC1B(O)O</smiles>

45 (Talabostat $^{\oplus}$ )<smiles>NC(CCC(=O)O)C(=O)N1CCCC1B(O)O</smiles>

46<smiles>O=C(CNC1CCNC1)N1CCCC1B(O)O</smiles><smiles>CC(C)(C)[N+](C)(C)C</smiles><smiles>CC(C)C[C@H](NC(=O)[C@H](Cc1ccccc1)NC(=O)c1cnccn1)[13C](C)([14CH3])O</smiles><smiles>Cc1ccc(B(OC(=O)c2ncccc2O)c2ccc(C)c(Cl)c2)cc1Cl</smiles> 